\title{
Planejamento e autoavaliação institucional: articulações possíveis e necessárias
}

\author{
Planning and institutional self-assessment: possible and necessary articulations
}

\author{
Fernanda Figueira Marquezan* \\ Greice Scremin $^{* *}$
}

\section{Resumo}

Este trabalho discute a necessária articulação entre uma proposta de autoavaliação e planejamento institucional de uma instituição de ensino superior (IES) comunitária do interior do Rio Grande do Sul. Trata-se de um estudo qualitativo de cunho bibliográfico, que se vale de obras referentes à avaliação e aos marcos regulatórios da educação superior e de documentos institucionais, sendo desenvolvido no contexto de uma comissão própria de avaliação. Este estudo foi efetivado para fins de qualificação do processo de autoavaliação, sendo materializado na atualização do Projeto de Autoavaliação Institucional da IES em questão. Os arranjos teóricos destacam o papel da autoavaliação como instrumento de gestão, bem como a compreensão de que o conhecimento da realidade institucional permite a melhoria da articulação entre as políticas de ensino, pesquisa e extensão. $O$ artigo destaca a necessidade da implementação de uma cultura avaliativa de caráter institucional que congregue a participação da comunidade por meio da colaboração no processo de autoavaliação e com subsídios para o planejamento institucional. Portanto, a qualidade acadêmica é perpassada pela coerência entre a missão, os princípios educativos e as políticas institucionais realizadas. Por fim, faz-se necessário possibilitar aos membros da comunidade acadêmica a autoconsciência de suas qualidades, dificuldades e desafios, a fim de aprimorar a cultura avaliativa.

Palavras-chave: Comissão própria de avaliação. Cultura avaliativa. Projeto de autoavaliação institucional.

\section{Abstract}

This paper discusses the necessary articulation between a proposal for self-assessment and institutional planning of a community IES in the interior of Rio Grande do Sul. This is qualitative study of a bibliographical nature. It is resorted on works related the evaluation and regulatory frameworks of higher education and institutional documents, developed in the context of an Own Evaluation Commission. This study was realized for the purpose of qualifying the self-assessment process, materialized in the update of the Institutional Self-assessment Project of the IES in question. Theoretical arrangements emphasize the role of self-assessment as a management tool, as well as the understanding that knowledge of the institutional reality allows for better articulation between teaching, research and extension policies. The article highlights the need to implement an institutional evaluation culture that congregates community participation through collaboration, both in the process of selfassessment and in the subsidies for institutional planning. Therefore, the academic quality is permeated by the coherence between the mission, the educational principles and the institutional policies realized. Finally, it is necessary to provide the members of the academic community to be self-conscience of their qualities, difficulties and challenges, in order to improve the evaluative culture.

Keywords: Own evaluation committee. Evaluative culture. Institutional self-assessment project.

\author{
Recebido em 20/05/2018 - Aprovado em 26/09/2018 \\ http://dx.doi.org/10.5335/rep.v26i1.8356
}

Doutora em Educação pela Pontifícia Universidade Católica do Rio Grande do Sul. Docente do Centro Universitário Franciscano e membro de grupo de pesquisa da Universidade Federal de Santa Maria. E-mail: marquezanfernanda@ gmail.com

** Doutora em Educação pelo Programa de Pós-Graduação em Educação da Universidade Federal de Santa Maria. Professora da rede pública municipal de Santa Maria e professora adjunta do Centro Universitário Franciscano. E-mail: greicescremin@gmail.com 


\section{Introdução}

Questões sociais, político-educacionais e tecnológicas, relacionadas à comunicação e à informação, vêm configurando a complexidade do mundo contemporâneo, de modo que as instituições de ensino superior (IES) são desafiadas a uma reconfiguração de espaços formativos de qualidade que transcendem a perspectiva tradicional do ensino, da pesquisa e da extensão. Tais configurações apresentam-se cada vez mais relacionadas às demandas de gestão para a qualidade da educação superior, bem como para atender a legislação vigente que avalia e regula esse nível de ensino, tornando, por isso, imprescindível os processos avaliativos, externos e internos, em que se destaca também a autoavaliação.

Trata-se de uma transição entre configurações em construção para o mundo contemporâneo e concepções refletoras de tendências históricas, caracterizando, assim, os contextos emergentes em educação superior, ${ }^{1}$ conforme Morosini (2014). Nesse sentido, destaca a autora que "[...] novos desafios estão postos, dos quais se destaca considerar as demandas locais num contexto global" (MOROSINI, 2014, p. 386). Para tanto, as universidades caracterizam-se como agências de desenvolvimento humano e social (BAWDEN, 2013).

No contexto institucional, a autoavaliação precisa ter caráter de diagnóstico mais amplo, de modo a refletir sobre a missão, os objetivos, a gestão acadêmica e o planejamento futuro, com intuito de viabilizar uma educação com a qualificação do ensino, da pesquisa, da extensão e da gestão universitária. Assim, é necessário que as IES desenvolvam um processo de autoavaliação contínuo de análises e reflexões sobre as suas atividades administrativas e pedagógicas, objetivando o aprimoramento institucional, a partir do conhecimento da realidade e de sua projeção.

Este artigo discute, nesse âmbito, uma proposta de autoavaliação articulada com o planejamento institucional de uma IES comunitária do interior do Rio Grande do Sul. Evidencia-se, no presente estudo, a necessidade de desenvolvimento de uma cultura avaliativa de caráter institucional que congregue a participação da comunidade por meio da colaboração no processo de autoavaliação e com subsídios para o planejamento institucional.

Trata-se de um estudo qualitativo de cunho bibliográfico, desenvolvido no contexto de uma comissão própria de avaliação (CPA). A abordagem metodológica utilizada foi a qualitativa, de cunho bibliográfico, porque, assim, torna-se possível compreender os aspectos da realidade que não podem ser quantificados, de modo a se promover o aprofundamento da compreensão e da explicação sobre o comportamento e as experiências humanas e também sobre as relações sociais constituídas. Tal abordagem possibilita a percepção e a compreensão humana (STAKE, 2011). 
A pesquisa bibliográfica consiste em identificar e conhecer as diferentes produções científicas acerca de um determinado tema ou assunto investigado, com o intuito de analisar as principais contribuições teóricas, de forma que o pesquisador possa utilizá-las para confirmar, refutar, confrontar ou enriquecer as suas proposições.

Para Lakatos e Marconi (2011), a pesquisa bibliográfica abarca toda bibliografia já publicada em relação à temática estudada e a sua principal função é colocar o pesquisador em contato com tudo o que foi produzido sobre tal assunto. Nesse sentido, utiliza-se do material já elaborado, em diversos tipos de fontes, constituído basicamente por livros, artigos, documentos oficiais, anais, meios eletrônicos, manuais (GIL, 2010).

Desse modo, para este estudo, valeu-se de: obras relacionadas a avaliação da educação superior, autoavaliação institucional, CPA, gestão universitária; documentos institucionais, como o Projeto Pedagógico Institucional (PPI), o Plano de Desenvolvimento Institucional (PDI) e os Projetos Pedagógicos dos Cursos (PPCs); e marcos regulatórios da educação superior, entre eles: Lei de Diretrizes e Bases da Educação Nacional (LDBEN), Lei no 9.394/1996, Sistema Nacional de Avaliação da Educação Superior (Sinaes), Lei no ${ }^{0}$ 10.861/2014.

Este estudo foi efetivado para fins de qualificação do processo de autoavaliação, sendo materializado na atualização do Projeto de Autoavaliação Institucional (PAI) da IES em questão. Tem-se, portanto, a necessidade do desenvolvimento de uma cultura avaliativa que permita florescer uma gestão colaborativa, uma vez que o diagnóstico institucional resulta da cultura investigativa, viabilizada no compromisso coletivo de concretizar o processo de apropriação crítica e reflexiva do conhecimento. Para isso, a instituição objeto deste estudo tem concentrado esforços no aperfeiçoamento de mecanismos que possibilitem imprimir, pela sensibilização da comunidade universitária, atitudes construtivas na concepção de avaliação como processo dinâmico para a melhoria da realidade. Essa concepção é necessária não só para reconhecer limites e comprovar potencialidades, mas também para permitir a construção de conhecimentos e a transformação de suposições em constatações pertinentes para a tomada de decisões.

Assim, em consonância com o PPI, os resultados da autoavaliação, bem como das avaliações externas, constituem-se como subsídios para a gestão acadêmico-administrativa, em face não só das mudanças de âmbito institucional, como também da realidade externa. Busca-se, ainda, aprimorar a cultura avaliativa a fim de envolver, cada vez mais, os atores, os sujeitos da comunidade acadêmica, em um processo de mobilização para o conhecimento crítico-reflexivo do desempenho global da instituição, diante dos aspectos sociais, éticos, culturais e acadêmicos de sua missão. 
O fortalecimento da cultura avaliativa e da gestão colaborativa envolve a avaliação da aprendizagem, do currículo, dos docentes e discentes, da infraestrutura e dos setores de apoio administrativo, dentre outros. É por meio da análise dos resultados que se possibilita o planejamento e a realização de novas ações para a sua melhoria e o seu aperfeiçoamento. Dessa forma, a proposta de autoavaliação institucional abarca aspectos fundamentais para a qualidade dos cursos superiores, a partir da abordagem de modo isonômico entre as modalidades presencial e educação a distância (EaD), visando estabelecer uma sistemática de autoavaliação institucional e de cursos, em seus variados eixos e dimensões.

Para tanto, o estudo teórico realizado para este artigo viabilizou a revisão e a atualização do PAI, de modo a expressar uma profunda reestruturação da programação sistemática de autoavaliação, para ambas as modalidades educacionais.

\section{Avaliação da educação superior: autoavaliação institucional}

No Brasil, o Sistema Nacional de Avaliação da Educação Superior (Sinaes) procura analisar as instituições, os cursos e o desempenho dos estudantes. O processo de avaliação leva em consideração aspectos como ensino, pesquisa, extensão, responsabilidade social, gestão da instituição e corpo docente. Esse sistema reúne informações do Exame Nacional de Desempenho de Estudantes (Enade) e das avaliações institucionais e dos cursos. As informações obtidas são utilizadas para orientação institucional de estabelecimentos de ensino superior e para embasar políticas públicas. Os dados também são úteis para a sociedade, especialmente aos estudantes, como referência quanto às condições de cursos e instituições.

Nesse contexto, é indicada a realização de avaliação das instituições de ensino brasileiras, servindo os procedimentos e os resultados dessa avaliação como fonte de informação e orientação de políticas públicas na área da educação.

A Lei no 10.861, de 14 de abril de 2004 (BRASIL, 2004) criou o Sinaes, com a função de aprimorar e ampliar o trabalho que já era realizado na área da avaliação da educação superior brasileira a partir do Programa de Avaliação Institucional das Universidades Brasileiras (Paiub). O Sinaes apresentou, assim, um modelo de avaliação com o intuito de desvincular avaliação de regulação.

O Sinaes é composto pela avaliação das instituições, dos cursos e do desempenho dos estudantes, tendo como incumbência avaliar todos os aspectos relacionados a ensino, pesquisa, extensão, responsabilidade social, desempenho dos alunos, gestão da instituição, corpo docente, instalações, entre outros (BRASIL, 2011). Nesse contexto, o principal princípio previsto para o trabalho avaliativo é a autonomia das instituições, atentando para a viabilização da gestão democrática e atendendo 
uma legislação vigente que busca permitir a transparência do serviço prestado, desvelando os erros e os acertos (BRASIL, 2011). A avaliação das IES está dividida em duas modalidades: autoavaliação e avaliação externa.

A autoavaliação institucional é coordenada pela CPA em cada instituição e orientada por um roteiro elaborado pela Comissão Nacional de Avaliação da Educação Superior (Conaes). Já a avaliação externa é realizada por comissões designadas pelo Instituto Nacional de Estudos e Pesquisas Educacionais Anísio Teixeira (Inep) e busca por padrões de qualidade expressos nos instrumentos de avaliação e nos relatórios das autoavaliações. Os processos avaliativos são coordenados e supervisionados pela Conaes, e a operacionalização é de responsabilidade do Inep.

Todo esse processo avaliativo é caracterizado por indicadores de qualidade avaliados a partir de uma escala contínua em cinco níveis ( 1 a 5). Esses indicadores servem de referência para avaliações in loco e também para a autoavaliação institucional, atendendo ao processo avaliativo proposto pelo Inep.

$\mathrm{Na}$ avaliação da instituição, são consideradas dez dimensões: missão e PDI; política para o ensino, a pesquisa, a pós-graduação e a extensão; responsabilidade social da IES; comunicação com a sociedade; políticas de pessoal e carreiras do corpo docente e técnico-administrativo; organização de gestão da IES; infraestrutura física; planejamento de avaliação; políticas de atendimento aos estudantes; e sustentabilidade financeira. Na avaliação dos cursos, são analisadas três dimensões: organização didático-pedagógica; perfil do corpo docente; e instalações físicas.

\section{A autoavaliação institucional}

A autoavaliação institucional é um processo coletivo de conhecimento, interpretação e reflexão sobre as ações desenvolvidas pela comunidade acadêmica, de maneira a ter como objetivo elevar a qualidade do ensino, da pesquisa, da extensão e da gestão. Nesse sentido, constitui um modo de trabalho acadêmico por meio do qual se constrói conhecimento sobre a própria realidade da academia e se institui em instrumento de aprimoramento da qualidade de todos os segmentos institucionais, pois sua função principal é educativa.

O processo de autoavaliação precisa ser uma fonte geradora de prioridades a partir da autorreflexão da comunidade acadêmica sobre o trabalho desenvolvido na instituição. Nessa perspectiva, a autoavaliação "[...] deve ter uma função muito mais crítica, que meramente de constatação. Deve analisar o realizado, mas para melhor cumprir o que há por realizar" (DIAS SOBRINHO, 2003, p. 180).

A autoavaliação institucional é uma proposta de visualização crítica da instituição diante da realidade e dos desafios da sociedade contemporânea. Por isso, 
como parte da concepção educativa e do PDI, a autoavaliação contribui para a sua concretização, uma vez que considera a necessidade de planejar o seu desenvolvimento com visão de presente e de futuro. Assim, a relevância desse processo para a melhoria da qualidade se caracteriza como "[...] uma prática social orientada, sobretudo para produzir questionamentos e compreender os efeitos pedagógicos, políticos, éticos, sociais, econômicos do fenômeno educativo" (DIAS SOBRINHO, 2003, p. 177).

Portanto, avaliar uma instituição significa ultrapassar a coleta de dados para se fazer análises e reflexões sobre as informações coletadas, com a intenção de potencializar os aspectos positivos e superar as dificuldades evidenciadas pelo processo avaliativo. Esse processo permite ainda a realização do acompanhamento das ações decorrentes dos processos de autoavaliação. Nessa perspectiva, a avaliação tem como postulado a problematização e a produção de sentidos, muito mais do que medidas e quantificações, e isso requer a colaboração ativa da comunidade acadêmica.

A autoavaliação faz parte de um projeto maior do desenvolvimento institucional, em que se deve considerar a vinculação com o desenvolvimento humano, ou seja, com as pessoas e o seu fazer universitário.

\section{Princípios e diretrizes da autoavaliação institucional}

A autoavaliação na IES fundamenta-se nos princípios institucionais, contidos no PPI, que evidenciam a constituição da identidade institucional e envolvem: autonomia, diversidade, ética, excelência, inserção, integralidade, sustentabilidade e meio ambiente, universalidade e internacionalização.

Além dos princípios institucionais, a autoavaliação está circunscrita pelos princípios estabelecidos pela Lei $n^{\circ}$ 10.861/2004, que institui o Sinaes, quais sejam: responsabilidade social com a qualidade da educação superior; reconhecimento da diversidade do sistema; respeito à identidade, à missão e à história das instituições; globalidade, isto é, a compreensão de que a instituição deve ser avaliada a partir de um conjunto significativo de indicadores de qualidade, vistos em sua relação orgânica e não de forma isolada; continuidade do processo avaliativo.

Desse modo, compreende-se que, para se atingir os propósitos da autoavaliação institucional, é necessário não só um conjunto de princípios e objetivos, mas também diretrizes que permitam o desencadeamento de um processo coerente, ético, colaborativo e transparente. De acordo com esse contexto, a avaliação institucional deverá se desenvolver por meio das seguintes diretrizes: 1) desenvolve-se por meio de um processo permanente, sistemático e dinâmico de consulta à comu- 
nidade universitária, adotando mecanismos que envolvam, de forma colaborativa, todos os segmentos institucionais, primando pela transparência do processo avaliativo; 2) não se constitui como instrumento de controle, punição ou premiação, mas conduz a instituição na busca da melhoria para o alcance de seus compromissos institucionais, com um caráter essencialmente formativo, ou seja, de estímulo ao desenvolvimento institucional e dos membros de sua comunidade; 3) é conduzida de forma integrada e isonômica entre as modalidades presencial e EaD, para evitar a fragmentação e abranger o contexto institucional global, de forma a evidenciar os aspectos críticos, as soluções desejadas e possíveis de serem realizadas, respeitadas as especificidades e peculiaridades; 4) é um instrumento de intervenção qualitativa no desenvolvimento do processo de construção e de solidificação e na qualidade de suas ações, no que se refere ao atendimento das demandas sociais; 5) realiza-se em consonância com as metas e os objetivos do PDI, a fim de ser um mecanismo permanente de garantia e desenvolvimento das políticas institucionais.

Nesse sentido, o objetivo central do processo de autoavaliação no contexto da instituição estudada trata de estabelecer a sistemática de autoavaliação institucional e de cursos, em seus variados eixos e dimensões. Esse propósito está desdobrado nos seguintes objetivos específicos: 1) conhecer a realidade institucional, buscando a melhoria da articulação entre as políticas de ensino, pesquisa e extensão; 2) avaliar a coerência entre a missão e as políticas educacionais realizadas, visando à melhoria da qualidade acadêmica; 3) aprimorar a cultura avaliativa no intuito de possibilitar aos membros da comunidade acadêmica autoconsciência de suas qualidades, dificuldades e desafios; 4) estabelecer mecanismos institucionalizados e colaborativos para a operacionalização da autoavaliação institucional; 5) desenvolver um processo de autoavaliação cíclico, crítico-reflexivo e renovador de análise e síntese das dimensões que definem a instituição, com caráter formativo e de autoconhecimento; 6) subsidiar a gestão institucional em face da realização de avaliações externas de regulação, por meio de diagnósticos e análises prévios de suas práticas institucionais, contribuindo para a qualidade da educação na instituição; 7) acompanhar as ações decorrentes dos processos avaliativos, sedimentando a relação da autoavaliação com a gestão institucional.

\section{Estrutura e dinâmica avaliativa}

O processo de autoavaliação na IES organiza-se, portanto, a partir de uma estrutura planejada, dentro de uma dinâmica que observa e contempla as demandas cotidianas da instituição, por meio da qual se contemplam os cinco eixos avaliativos propostos para integrar as dimensões da avaliação, de acordo com o Sinaes: 
a) Eixo 1 - Planejamento e avaliação institucional (Dimensão 8 - Planejamento e autoavaliação; relato institucional);

b) Eixo 2 - Desenvolvimento institucional (Dimensão 1 - Missão e PDI; Dimensão 3 - Responsabilidade social);

c) Eixo 3 - Políticas acadêmicas (Dimensão 2 - Ensino, pesquisa e extensão; Dimensão 4 - Comunicação com a sociedade; Dimensão 9 - Políticas de atendimento aos estudantes);

d) Eixo 4 - Políticas de gestão (Dimensão 5 - Políticas de pessoal e carreira do corpo docente e técnico-administrativo; Dimensão 6 - Políticas de gestão; Dimensão 10 - Sustentabilidade financeira);

e) Eixo 5 - Infraestrutura (Dimensão 7 - Infraestrutura).

Desse modo, esse processo envolve um conjunto de ações planejadas e desenvolvidas de forma conexa entre si e que busca o envolvimento e a colaboração da comunidade acadêmica, conforme a sistematização da Figura 1.

Figura 1 - Estrutura e dinâmica avaliativa

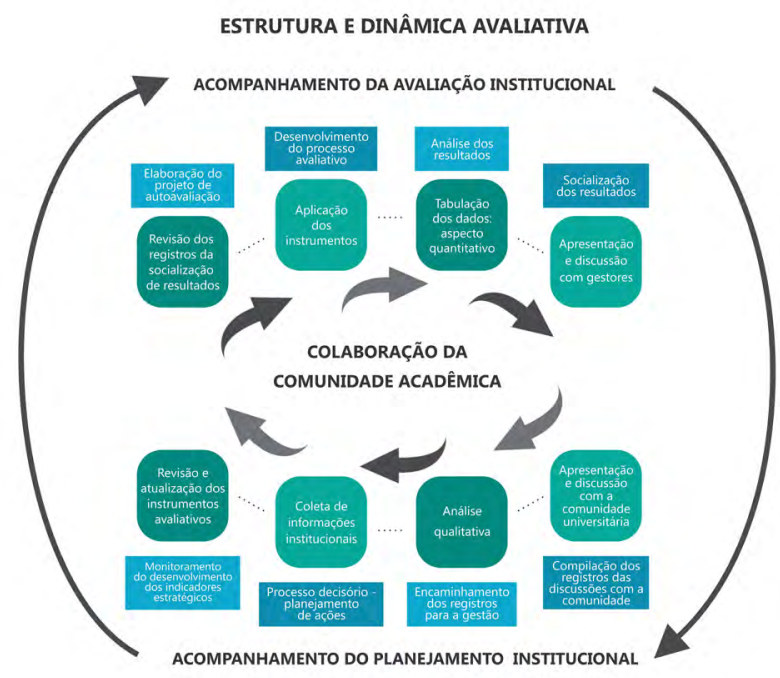

Fonte: elaboração das autoras, 2016. 


\section{Envolvimento e colaboração da comunidade acadêmica}

A autoavaliação estabelece as bases para a construção coletiva de uma cultura avaliativa, sob a coordenação da CPA, com as seguintes ações colaborativas:

a) elaboração do PAI - esse projeto tem caráter flexível e dinâmico, a fím de incorporar novas demandas da IES, tendo em vista a evolução institucional; desse modo, as revisões periódicas que geram reformulações do PAI são realizadas assegurando-se a representatividade de todos os segmentos da comunidade acadêmica (professores, funcionários técnico-administrativos e estudantes) por meio da CPA;

b) desenvolvimento do processo avaliativo - revisão e criação de instrumentos de autoavaliação: os instrumentos de autoavaliação são previstos no PAI, porém são realizadas revisões com periodicidade anual, bem como a criação de novos instrumentos que contemplem as demandas institucionais; essas revisões contam com a participação de pró-reitores, diretores de unidade, coordenadores de cursos, professores e estudantes representantes da CPA e equipe consultiva; aplicação dos instrumentos de autoavaliação: a aplicação é realizada de forma on-line no sistema interno da instituição para toda a comunidade acadêmica; a CPA, juntamente com a Unidade de Tecnologia da Informação, disponibiliza os instrumentos e acompanha a participação da comunidade, com a frequente divulgação dos instrumentos para coordenadores de cursos e diretores de unidades, para que conscientizem professores, estudantes e funcionários sobre a relevância de participar da autoavaliação; a sensibilização de gestores (coordenadores de cursos, Núcleos Docentes Estruturantes - NDEs e diretores de unidades) para responder aos instrumentos fica a cargo da CPA;

c) análise dos resultados - após a tabulação dos resultados pela Unidade de Tecnologia da Informação, os dados e as informações são repassados à CPA, para fins de disseminação aos cursos e/ou setores; a análise dos resultados específicos fica a cargo de cada curso/setor; a análise dos dados institucionais é realizada pela CPA, com participação de seus representantes;

d) socialização dos resultados - a CPA sistematiza as informações que serão socializadas e discutidas com os gestores (coordenadores de curso, NDEs e diretores de unidades) e com estudantes representantes dos cursos (colegiados e diretórios acadêmicos); esses atuam como disseminadores dos resultados e das discussões para seus pares, no contexto dos cursos; a comunidade acadêmica também participa do registro das discussões que retroalimentam a autoavaliação institucional, inclusive no âmbito dos cursos. 


\section{Socialização dos resultados}

Compreende-se que o processo de socialização envolve não só a apresentação dos resultados, como também a discussão desses dados que retroalimentam as ações de planejamento e avaliação.

Assim, a CPA é responsável por sistematizar as informações coletadas para ampla divulgação para a comunidade universitária e o MEC. Nesse sentido, o Relatório de Autoavaliação será submetido anualmente, por meio do Sistema e-MEC, ao longo de um período de três anos. Nos dois primeiros anos, o relatório deverá ser inserido em sua versão parcial; já no terceiro ano, em sua versão integral.

A divulgação/discussão dos resultados envolve a interação da CPA com a gestão dos cursos e de setores administrativos, bem como com a representação de estudantes de colegiados e diretórios acadêmicos. Essa interação tem o objetivo de estimular o desenvolvimento da cultura de avaliação por meio da disseminação das discussões sobre autoavaliação, já que se cria uma rede de comunicação sobre a temática. Ainda a respeito da socialização dos resultados, faz-se necessário o registro sistematizado das discussões suscitadas, pois, a partir dele, é possível o encaminhamento de ações de planejamento.

\section{Evolução institucional a partir da articulação entre autoavaliação e planejamento}

A avaliação institucional caracteriza-se como um processo sistemático e contínuo, que possibilita a reflexão sobre as atividades desenvolvidas pela comunidade acadêmica e pela administração institucional. Constitui-se, também, em um repensar das atividades desenvolvidas, pois objetiva superar os aspectos diagnosticados como merecedores de maior atenção, o que permite o aperfeiçoamento permanente da qualidade institucional.

A realização da autoavaliação, na IES, iniciou-se pela graduação no ano de 1999 e envolveu três dimensões: disciplinas, desempenho docente e autoavaliação discente. Com os resultados dessas avaliações, encaminharam-se estratégias de mudança para a melhoria dos cursos preexistentes e criação de novos cursos, tendo em vista a autonomia da IES. Dessa forma, a autoavaliação institucional ofereceu subsídios para complementar o planejamento sistematizado no PDI 1997-2002. No que tange aos processos de autoavaliação, no ano de 2001, iniciou-se a avaliação dos cursos de pós-graduação lato sensu, tornando-se sistemática nos cursos de especialização oferecidos pela instituição. Os resultados dessas avaliações permitiram a qualificação dos cursos ofertados e a projeção de novos cursos lato sensu, além de apontarem para a viabilidade da criação e implementação dos futuros cursos 
stricto sensu. Dessa forma, os resultados da autoavaliação vêm possibilitando o planejamento e a implementação de ações que permitem fazer ajustes, criar novas estratégias de ação e, assim, instaurar a renovação permanente da qualidade acadêmica e da gestão universitária.

Posterior a esse período, a implantação do Sinaes no país proporcionou à instituição a oportunidade de reelaboração do projeto de autoavaliação. O PAI foi, então, atualizado, ampliando as funções e os níveis de abrangência para desenvolver um estudo mais aprofundado, tendo em vista o aprimoramento da missão institucional e da qualificação da educação superior.

Assim, desde 1999, o processo de autoavaliação da instituição orienta-se pelo PAI e, atualmente, tem por referenciais o PPI, o PDI e as diretrizes do Sinaes.

O processo de autoavaliação na IES tem sido coordenado pela CPA, constituída, de acordo com a Lei no 10.861, de 14 de abril de 2004, Art. 11, por quatro representantes do corpo docente, dois representantes do corpo técnico-administrativo, três representantes do corpo discente e um membro da sociedade civil organizada. $\mathrm{Na}$ IES em tela, os membros são nomeados pelo reitor, sendo que os representantes do corpo discente são indicados pelo Diretório Central dos Estudantes e nomeados pelo reitor. Os mandatos dos componentes da CPA são de dois anos, podendo haver recondução. A CPA conta, na IES, com o apoio da equipe consultiva, nomeada pelo reitor e constituída por quatro docentes representantes das áreas de conhecimento, pelo pesquisador institucional, pelo assessor de planejamento e por um representante da Unidade de Tecnologia da Informação. Suas ações buscam estimular a cultura avaliativa na instituição, colaborando com a CPA no desenvolvimento do processo de autoavaliação institucional.

Em sua trajetória, a CPA tem coordenado a autoavaliação institucional de acordo com os seguintes princípios:

a) preservação dos valores acadêmicos fundamentais, de liberdade e pluralidade de ideias, que se manifestam no cultivo da reflexão filosófica e do conhecimento científico e cultural;

b) respeito e valorização da ética, da expressão e do pensamento crítico;

c) transparência e fidedignidade das informações coletadas no processo avaliativo;

d) atuação autônoma, em relação aos conselhos e demais órgãos colegiados existentes na instituição;

e) compromisso com a qualidade da educação superior.

Assim, a CPA tem seu regulamento próprio, com a finalidade de condução dos processos avaliativos internos da instituição, de sistematização e de prestação das 
informações solicitadas pelo Inep. Os objetivos que orientam o trabalho da CPA são:

a) desenvolver, de forma sistemática e permanente, a avaliação institucional como processo de autoconhecimento e de autocrítica da instituição, tendo em vista o aprimoramento das funções de ensino, pesquisa, extensão e gestão;

b) aprimorar a cultura avaliativa, na perspectiva de possibilitar aos membros da comunidade acadêmica autoconsciência de suas qualidades e de seus desafios do presente e do futuro, estabelecendo mecanismos institucionalizados e participativos para a sua operacionalização;

c) oportunizar à comunidade universitária, por meio de um processo avaliativo, diagnóstico e formativo, a análise de suas práticas acadêmicas e administrativas, tendo em vista a qualidade da educação superior na instituição.

Essa nova configuração do processo de autoavaliação possibilitou a construção de um conhecimento mais aprofundado sobre as potencialidades da instituição. Nesse sentido, nos relatórios de autoavaliação elaborados entre os anos de 2004 a 2007, observou-se um destaque para a necessidade de fortalecimento da cultura institucional interna. Portanto, os resultados da autoavaliação institucional promoveram a organização do PDI 2008-2011, com opções orientadoras que revelaram o compromisso educacional da instituição, conjugando as novas bases legais ( $\mathrm{Si}$ naes) com a missão, os objetivos e as metas.

Os resultados dos processos de autoavaliação do período de 2008 a 2013 apontaram para a necessidade de aprimoramento da cultura avaliativa que contemplasse a gestão, o ensino, a pesquisa e a extensão, como forma de revitalizar e inovar os mecanismos de gestão acadêmico-administrativa. Outro aspecto destacado nas avaliações tratou de evidenciar o crescimento da atividade universitária, o que demandou a projeção da qualificação profissional dos colaboradores.

Em 2009, a IES passou por um processo de recredenciamento institucional, em que a avaliação apontou para a ausência de cursos na modalidade $\mathrm{EaD}$ ou apoio ao ensino presencial. Esse aspecto foi projetado para ser desenvolvido a partir do PDI 2012-2015, no qual constam as ações voltadas ao credenciamento institucional para a oferta de cursos a distância. Também foi pontuada a fragilidade da padronização no processo de autoavaliação de cursos de graduação, sendo que, a partir desse período, os PPCs foram elaborados contemplando o processo de autoavaliação, e a CPA orientou e sistematizou a produção dos relatórios de autoavaliação dos cursos de graduação. Ainda referente ao recredenciamento do ano de 2009, houve a sinalização da necessidade de o plano de carreira estar registrado e homologado por órgão competente, sendo que essa ação foi prevista e implementada no ano de 
2013. Outro aspecto apontado pela comissão de avaliação externa foi em relação ao conhecimento dos estudantes sobre os resultados do processo avaliativo. Dessa forma, o PDI de 2012-2015 teve indicadores que efetivaram o planejamento de ações voltadas para uma concepção sistêmica de avaliação institucional, com foco nos estudantes.

Nessa caminhada, a CPA desenvolveu um processo avaliativo, formativo e reflexivo, que impulsionou o crescimento da instituição de forma transparente e consistente, em todas as suas instâncias administrativas, pedagógicas, científicas e tecnológicas.

Conforme a evolução institucional evidencia, a articulação entre planejamento e avaliação é compreendida na interação entre essas dimensões da gestão universitária. Desse modo, percebe-se que o processo de autoavaliação tem evoluído e se fortalecido em cumprimento ao seu papel de contribuir com o planejamento institucional. Sendo assim, compreende-se que o conhecimento gerado por esse processo tem permitido à comunidade universitária perceber a relevância educacional, científica, social e tecnológica de suas atividades, bem como tornar mais efetiva a relação da instituição com a sociedade.

No tocante à autoavaliação, busca-se facilitar o processo de discussão e análise entre os membros da comunidade acadêmica, construindo a cultura avaliativa, agregando valor às diversas atividades da instituição como um todo. Busca-se, também, identificar aspectos fundamentais para a qualidade dos cursos superiores e propor um processo contínuo de avaliação, envolvendo os âmbitos dos cursos presenciais e EaD.

Nessa perspectiva, o acompanhamento e a avaliação do planejamento e a execução do trabalho são realizados conforme definição sistemática nos documentos institucionais: PPI, PDI, Estatuto, regimentos e demais documentos, com destaque para o PAI, que aborda esse processo pelo prisma da avaliação e dos resultados correlatos, a partir de um conjunto de indicadores relativos à atuação dos profissionais docentes, aplicáveis quando há as avaliações internas na IES.

Portanto, a trajetória de autoavaliação da IES evidencia que, por meio da elaboração e reelaboração do PAI, em um primeiro momento, buscava-se instituir uma sistemática de autoavaliação baseada em leitura, análise e reflexão crítica da realidade. O segundo período foi marcado pela instituição do Sinaes, em que a autoavaliação ampliou suas funções e os seus níveis de abrangência. O terceiro momento demandou a atualização do PAI, tendo em vista a projeção da instituição na EaD, desenvolvendo, assim, a isonomia entre as modalidades de ensino na autoavaliação. 
Considerando que a IES consolidou sua organização acadêmica (com destaque para a pós-graduação stricto sensu, em sua correlação com o desenvolvimento de pesquisas científicas), tem histórico de avaliações com conceitos superiores e crescentes, tem o reconhecimento da sociedade; firma sua imagem em âmbito nacional e projeta-se no cenário internacional, o que justifica seu amadurecimento e sua aptidão para a transformação em universidade.

Portanto, diante do desafio emergente de continuar o seu processo de evolução, considera-se que a autoavaliação institucional contribuirá na consolidação da qualidade acadêmica da IES, para a articulação entre ensino, pesquisa e extensão e para a gestão do planejamento institucional. Nesse sentido, a evolução institucional em relação ao processo de planejamento e avaliação institucional configura-se em uma estratégia capaz de atender às necessidades institucionais, ou seja, como instrumento de gestão e de ações acadêmico-administrativas de melhoria institucional, apresentando resultados, análises, reflexões e proposições de forma a subsidiar planejamentos e ações (NUNES; DUARTE; PEREIRA, 2017).

Destaca-se, assim, a necessidade de a autoavaliação institucional avançar no acompanhamento das ações dela decorrentes, buscando ampliar os aspectos da sua relação com a gestão institucional. Assim, a revisão e a reestruturação do PAI são necessárias, tendo em vista o momento de transformação da IES e as necessidades de embasar e justificar o trabalho desenvolvido pela CPA.

\section{Planejamento de ações a partir dos resultados do processo avaliativo}

A articulação entre o planejamento e a avaliação institucional se materializa no desenvolvimento de ações planejadas a partir dos resultados do processo avaliativo, sejam eles originários de avaliações internas ou externas. Isso significa que a articulação entre planejamento e avaliação institucional se dá em complementariedade aos processos de avaliação externa e interna, com vistas ao cumprimento e à consolidação da sua missão.

Assim sendo, a autoavaliação subsidia o planejamento de acordo com as diretrizes pedagógicas e de gestão expressas no PPI, tais como:

a) as ações de autoavaliação institucional subsidiam o ensino, a pesquisa, a extensão, a gestão e o acompanhamento global do desempenho institucional, que são planejados e materializados a partir do conhecimento da realidade concreta de cada setor que compõe a estrutura organizacional;

b) a autoavaliação possibilita o conhecimento acerca da qualidade e da utilização dos espaços institucionais que têm o propósito de uma formação profissional consistente diante das necessidades emergentes do mundo contemporâneo; 
c) o PPC se caracteriza como a base de gestão acadêmico-administrativa dos cursos e deve estar em constante processo de autoavaliação, no sentido de: avaliar a promoção da confluência dos componentes que materializam a sua estrutura curricular; avaliar a sua constituição como um dos elementos que definem e operacionalizam parte das metas do PDI; avaliar a sua função de instrumento operacional, a partir do qual as políticas e ações programadas pela comunidade acadêmica são processadas, acompanhadas e avaliadas;

d) os resultados das avaliações externas e internas fornecem subsídios para a organização da estrutura curricular e pedagógica dos cursos, respeitadas as diretrizes curriculares nacionais e a missão da instituição, assim como os programas de pesquisa e de extensão, a fim de permitir a integração e a retroalimentação entre ensino-pesquisa-extensão;

e) a autoavaliação contribui no diagnóstico essencial para a criação, a expansão e a extinção de cursos, consideradas as capacidades e competências técnico-científicas dos cursos em manter uma formação de qualidade;

f) os processos de autoavaliação dos cursos de graduação contribuem para qualificar a formação inicial, considerando que os processos de educação e profissionalização devem ser permanentes;

g) a autoavaliação institucional identifica a qualidade da colaboração mútua entre graduação e pós-graduação, mediada por ensino, pesquisa e extensão, em vista do aperfeiçoamento da formação profissional desses níveis de ensino;

h) o processo de autoavaliação no curso reconhece se a organização curricular expressa, de forma objetiva, a indissociabilidade entre o ensino, a pesquisa e a extensão, bem como a flexibilização curricular;

i) a partir dos resultados da autoavaliação, é possível perceber se a dinâmica curricular dos cursos de graduação possibilita a introdução de novas formas e metodologias de aprendizagem, que agreguem a pesquisa e a extensão;

j) a avaliação da pesquisa e da extensão identifica a qualidade da cooperação entre as áreas de conhecimento ofertadas pela instituição, bem como as relações com a comunidade e a promoção de parcerias interinstitucionais e internacionais;

k) a autoavaliação permite identificar se as atividades curriculares complementares ofertadas suprem possíveis lacunas da estrutura curricular e se elas se constituem como espaços da dinâmica curricular voltados ao desenvolvimento de conteúdos, atividades socioculturais e temas emergentes;

l) o processo de autoavaliação reconhece se os estágios curriculares se constituem como um conjunto de atividades teórico-práticas, que visa à superação de possíveis distanciamentos entre o pensamento e a ação, e também se promovem a aproximação concreta com o campo de trabalho; 
m) a avaliação docente subsidia o desenvolvimento dos programas permanentes de capacitação pedagógica que estão em consonância com os programas de apoio a inovações pedagógicas;

n) a autoavaliação da infraestrutura identifica a qualidade da atualização do acervo bibliográfico, dos laboratórios de ensino e de pesquisa e dos setores de informática e multimídia;

o) a avaliação da gestão acadêmico-administrativa reconhece a operacionalização dos princípios de liderança proativa, gestão colaborativa, autonomia e compromisso;

p) a avaliação da gestão acadêmico-administrativa dos cursos verifica o caráter pedagógico e cultural e permite identificar o modo como ocorre a mediação entre o PPI, o PDI e o PPC, consoante as estratégias e ações do PAI;

q) os projetos de autoavaliação dos cursos são parte integrante dos respectivos projetos pedagógicos e estão voltados ao estudo do conjunto das ações processuais que envolvem a especificidade da organização didático-pedagógica dos cursos. A execução do projeto de autoavaliação ocorre simultaneamente à progressão do PDI, do Plano de Gestão, dos PPCs e dos resultados provenientes das avaliações internas e externas.

A articulação entre planejamento e avaliação é, portanto, compreendida por meio da interação entre essas dimensões da gestão universitária, conforme se pode observar na Figura 2.

Figura 2 - Articulação entre planejamento e avaliação

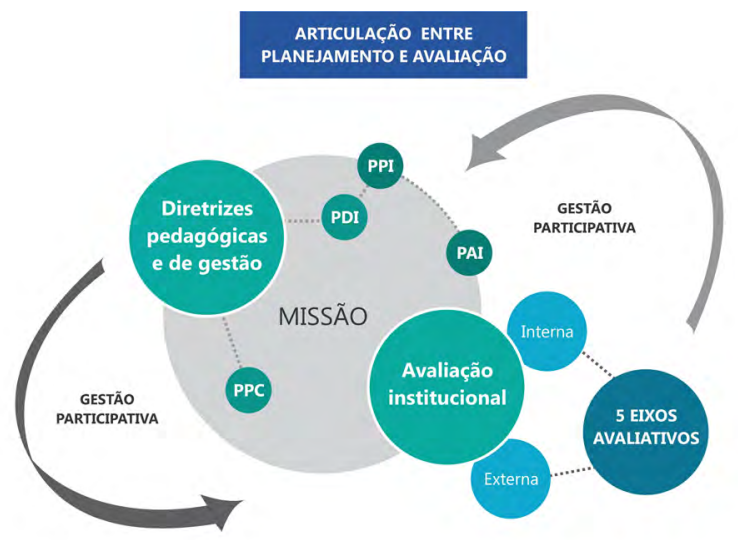

Fonte: elaboração das autoras, 2016. 
Com base no exposto, a Figura 2 evidencia a relevância da articulação entre o planejamento e a avaliação institucional, amparada na missão, nos documentos institucionais, via gestão participativa, uma vez que, de acordo com Cavalieri, Macedo-Soares e Thiollent:

Uma avaliação internalizada pode gerar informações para servir de base de apoio para o planejamento de médio ou longo prazos. Avaliações bem concebidas e realizadas com a participação ativa das comunidades envolvidas podem fornecer relevantes subsídios para diferentes modalidades de planejamento, em particular quando se trata de redesenhar o futuro de determinadas atividades universitárias (2004, p. 98).

Desse modo, percebe-se que o processo de autoavaliação tem evoluído e se fortalecido em cumprimento ao seu papel de contribuir com o planejamento institucional. Compreende-se que o conhecimento gerado por esse processo tem permitido à comunidade universitária perceber a relevância educacional, científica, social e tecnológica de suas atividades, bem como tornar mais efetiva a relação da instituição com a sociedade.

Nessa perspectiva, a articulação entre o planejamento e a avaliação institucional busca assegurar o alinhamento de ações, projetos e programas definidos a partir da missão, das estratégias de desenvolvimento e das diretrizes pedagógicas. Trata-se, dessa forma, de um instrumento de gestão que propicia que a instituição demonstre à comunidade interna e externa, com clareza, onde deseja chegar e quais serão os investimentos futuros (BOLDINI, 2003).

Assim, compreende-se que é por meio da articulação com o planejamento que a instituição atingirá o amadurecimento da cultura avaliativa institucional, visto que a "[...] universidade é compreendida como um conjunto de processos e relações que se produzem em seu cotidiano" (DIAS SOBRINHO, 2003, p. 15). Nesse sentido, constata-se que a avaliação institucional é uma prática necessária ao cotidiano da universidade, uma vez que se trata de um processo que permite a reflexão sobre sua realidade da instituição, de modo que exigirá, de todos os atores implicados (docentes, discentes e técnico-administrativos), o compromisso com o conhecimento e com o consequente aprimoramento dessa mesma realidade (BELLONI, 1999). Nesse contexto, universidade passa a ser concebida como uma instituição que aprende consigo, via análise e reflexão sistemática dos resultados, que busca identificar suas potencialidades e fragilidades, de modo a manter o seu aperfeiçoamento e a busca de melhorias para a educação superior. 


\section{Notas conclusivas}

Tendo em vista o nível elevado de padrão de qualidade acadêmica que a instituição vem consolidando, destaca-se a sua importância como agente de desenvolvimento. Nesse sentido, a IES tem se lançado em um novo patamar de desafios, no que tange à sua contribuição para a solução das demandas de desenvolvimento socioeconômico, tecnológico e cultural, nos níveis regional, nacional e internacional. A contribuição nesses aspectos ocorre por meio da preparação de cidadãos para um contexto globalizado e interdependente em relação à ciência, à cultura e à convivência com povos de outras nações, fundamentado em valores humanos universais.

Essa vigorosa atuação demanda uma organização sedimentada na articulação entre o planejamento e a avaliação institucional, pois essa nova configuração possibilita que a CPA participe efetivamente do gerenciamento do processo de planejamento institucional, por meio de ações com o objetivo de gerar resultados que subsidiem o processo decisório da IES. Nesse sentido, possibilita também monitorar o desenvolvimento dos indicadores estratégicos, orientando ações corretivas em relação aos objetivos estabelecidos com base no gerenciamento dos processos de avaliação institucional em colaboração com a CPA.

Nesse contexto, o PAI destaca o papel da autoavaliação como instrumento de gestão, bem como sistematiza o processo de autoavaliação institucional. Compreende-se que o conhecimento da realidade institucional permite a melhoria da articulação entre as políticas de ensino, pesquisa e extensão. Portanto, a qualidade acadêmica é perpassada pela coerência entre a missão, os princípios educativos e as políticas institucionais realizadas. Nesse contexto, faz-se necessário possibilitar aos membros da comunidade acadêmica a autoconsciência de suas qualidades, dificuldades e desafios, a fim de aprimorar a cultura avaliativa.

O papel da autoavaliação está em acompanhar as ações decorrentes dos processos avaliativos, sedimentando a relação da autoavaliação com a gestão institucional. Assim, a articulação entre planejamento e avaliação é compreendida como um processo de mobilização para o conhecimento crítico-reflexivo da realidade institucional, tendo em vista a qualificação da educação superior.

\section{Nota}

1 Os contextos emergentes da educação superior, de acordo com Morosini (2014), são considerados espaços de transição entre um modelo - tipo ideal weberiano - de educação tradicional (voltada ao bem social, ao desenvolvimento científico) e outro de educação superior neoliberal (voltada ao bem individual e ao espaço de realização pessoal, satisfazendo os perfis do mercado de trabalho, centrada na transferência de tecnologia e prestação de serviços ao setor estatal). 


\section{Referências}

BAWDEN, Richard. O objetivo educador da educação superior para o desenvolvimento humano e social no contexto da globalização. In: GLOBAL UNIVERSITY NETWORK FOR INNOVATION (GUNI). Educação superior em um tempo de transformação: novas dinâmicas para a responsabilidade social. Trad. Vera Muller. Porto Alegre: EDIPUCRS, 2009. p. 49-52.

BELLONI, Isaura. Avaliação institucional: um instrumento de democratização da educação. $L i$ nhas Críticas, Brasília, DF, v. 5, n. 9, p. 7-30, jul./dez. 1999.

BOLDINI, Vera. Planejamento estratégico nas universidades. 2003. Disponível em: <http://www. abepro.org.br/biblioteca/ENEGEP1998_ART139.pdf>. Acesso em: 13 jul. 2018.

BRASIL. Instituto Nacional de Estudos e Pesquisas Educacionais Anísio Teixeira. Educação Superior. Avaliação Institucional. Brasília, DF: Inep, 2011. Disponível em: <http://portal.inep. gov.br/superior-avaliacao_institucional>. Acesso em: 18 jun. 2017.

Lei nํ 9.394, de 20 de dezembro de 1996. Estabelece as Diretrizes e Bases da Educação Nacional. Brasília, DF, 1996. Disponível em: <http://www.planalto.gov.br/ccivil_03/leis/L9394. htm>. Acesso em: 24 maio 2017.

Ministério da Educação. Lei no 10.861 , de 14 de abril de 2004. Institui o Sistema Nacional de Avaliação da Educação Superior - Sinaes e dá outras providências. Brasília, DF, 2004. Disponível em: <http://www.planalto.gov.br/ccivil_03/_ato2004-2006/2004/lei/110.861.htm>. Acesso em: 24 maio 2017.

CAVALIERI, Adriane; MACEDO-SOARES, T. Diana L. v. A.; THIOLLENT, Michel. Avaliando o desempenho da universidade. Rio de Janeiro: PUC-Rio; São Paulo: Loyola, 2004.

DIAS SOBRINHO, José. Avaliação: políticas educacionais e reformas da educação superior. São Paulo: Cortez, 2003.

GIL, Antônio Carlos. Como elaborar projetos de pesquisa. 5. ed. São Paulo: Atlas, 2010.

LAKATOS, Eva Maria. MARCONI, Marina de Andrade. Metodologia científica. 6. ed. São Paulo: Atlas, 2011.

MOROSINI, Marília Costa. Qualidade da educação superior e contextos emergentes. Avaliação, Campinas; Sorocaba, SP, v. 19, n. 2, p. 385-405, jul. 2014.

NUNES, Enedina Betânia Leite de Lucena Pires; DUARTE, Michelle Matilde Semigueem Lima Trombini; PEREIRA, Isabel Cristina Auler. Planejamento e avaliação institucional: um indicador do instrumento de avaliação do Sinaes. Avaliação, Campinas; Sorocaba, SP, v. 22, n. 2, p. 373-384, jul. 2017.

STAKE, Robert. Pesquisa qualitativa: estudando como as coisas funcionam. São Paulo: Penso, 2011. 